\title{
Expression of a Serratia marcescens Chitinase Gene in Sinorhizobium fredii USDA191 and Sinorhizobium meliloti RCR2011 Impedes Soybean and Alfalfa Nodulation
}

\author{
Hari B. Krishnan, Kil Yong Kim, and Ammulu Hari Krishnan \\ Department of Plant Pathology, University of Missouri, Columbia 65211, U.S.A. \\ Accepted 28 April 1999.
}

\begin{abstract}
A gene encoding chitinase from Serratia marcescens BJL200 was cloned into a broad-host-range vector (pRK415) and mobilized into Sinorhizobium fredii USDA191. Chitinolytic activity was detected in $S$. fredii USDA191 transconjugants that carried the $S$. marcescens chiB gene. Chitinase-producing $S$. fredii USDA191 formed nodules on soybean cultivar McCall. However, there was a delay in nodule formation and a marked decrease in the total number of nodules formed by the chitinaseproducing $S$. fredii in comparison with the wild-type strain. Expression of chitinase in S. meliloti RCR2011 also impeded alfalfa nodulation. Thin-layer chromatography of ${ }^{14}$ C-labeled Nod factors from chitinase-producing $S$. fredii USDA191 revealed hydrolysis of lipochitooligosaccharides.
\end{abstract}

Pesticides are widely used to control plant diseases. However, most pesticides are hazardous to the health of humans and animals. They also have deleterious effects on ecological systems. Biological control promises to be a useful alternative approach in the control of plant pathogens (Weller 1988). Chitin, a $\beta$-1,4-linked polymer of $N$-acetyl glucosamine (GlcNAc), is an important structural component of insects, fungi, and nematodes (Monreal and Reese 1969). Several organisms, including higher plants, fungi, and bacteria, produce chitinases (EC 3.2.1.14) that cleave the glycosidic bonds in the chitin chain by either an endolytic or exolytic mechanism (Monreal and Reese 1969). It has been shown that application of chitin can reduce plant disease caused by certain soil fungi and nematodes (Mian et al. 1982;, Shapira et al. 1989). This beneficial effect has been attributed to proliferation of organisms that secrete chitin-degrading enzymes (Mankau and Das 1969; Mercer et al. 1992; Miller and Sands 1977). Based on

Corresponding author: Hari B. Krishnan; Address: Department of Plant Pathology, 108 Waters Hall, University of Missouri, Columbia 65211, U.S.A. Telephone: 1-573-882-2862; Fax: 1-573-882-0588

E-mail: KrishnanH@missouri.edu

Current address of Kil Yong Kim: Department of Agricultural Chemistry, Chonnam, National University, Kwangju 500-757, Republic of Korea. the potential role of chitinase as an anti-fungal agent (Schlumbaum et al. 1986; Broglie et al. 1991), attempts have been made to express chitinase genes in rhizospherecolonizing soil bacteria to control pathogenic fungi (Fuchs et al. 1986; Sitrit et al. 1993).

Serratia marcescens, a gram-negative bacterium, is very efficient in the degradation of chitin because of its ability to produce different chitinolytic enzymes. Two chitinase genes (chiA and $c h i B$ ) have been isolated from $S$. marcescens (Jones et al. 1986; Brurberg et al. 1995). Inactivation of one of the chitinase genes greatly reduced the ability of this bacterium to inhibit the growth of Fusarium oxysporum f. sp. pisi (Fop), a fungal pathogen (Jones et al. 1986). Attempts have also been made to express the $S$. marcescens chitinase in Pseudomonas spp. and plant symbiotic bacteria such as Rhizobium spp. to control soil pathogens (Fuchs et al. 1986; Sitrit et al. 1993). It was proposed that, since Rhizobium spp. can efficiently colonize the roots of hosts and nonhosts in large numbers, they could serve as a powerful biocontrol agents. Sitrit et al. (1993) expressed the chiA gene from $S$. marcescens in $R$. meliloti and have demonstrated that the nodule extracts from chiA expressing alfalfa plants caused lysis of Rhizoctonia solani hyphal tips. Interestingly, chitinase-producing $R$. meliloti strains also had no effect on alfalfa symbiosis. This observation is intriguing since rhizobium-induced nodule formation in legumes is initiated by Nod factors, which are modified oligomers of $\mathrm{N}$-acetylgucosamine (GlcNAc). Nod factors can be hydrolyzed by chitinases (Staehelin et al. 1994; Minic et al. 1998). Hence, the expression of chitinase genes in $R$. meliloti may lead to the breakdown of the Nod factors that will lead to defective symbiosis. We therefore decided to examine the consequences of expressing the chitinase gene in Sinorhizobium fredii USDA191 on soybean symbiosis.

A plasmid (pMAY2-10) containing the chiB gene of $S$. marcescens BJL200 (Sundheim et al. 1988) as a 1.8-kb EcoRI/MluI fragment in pGEM-7f (+) was obtained from May Brurberg (Agricultural University of Norway). This plasmid was digested with EcoRI and HindIII and recloned into pRK415, a broad-host mobilizable vector (Keen et al. 1988), digested with the same enzymes. The resulting plasmid was named pSMC1 and mobilized into $S$. fredii USDA191 by tri- 
parental mating with the helper plasmid pRK2013. Transconjugants, which were resistant to tetracycline, were grown in YEM (Vincent 1970) media. S. fredii USDA191(pRK415) and USDA191(pSMC1) exhibited similar growth characteristics and had identical doubling time. In order to see whether the chitinase gene was being expressed in S. fredii USDA191, we performed a highly sensitive silver stain method for detecting chitinolytic activity after sodium dodecyl sulfate-polyacrylamide gel electrophoresis (SDS-PAGE; Marek et al. 1995). Three-day-old, 5-ml cultures of $S$. fredii USDA191 containing chiB and pRK415 were centrifuged and the pellet was resuspended in $500 \mu \mathrm{l}$ of SDS-sample buffer without $\beta$-mercaptoethanol. The samples were boiled for $5 \mathrm{~min}$ and $10 \mu \mathrm{l}$ aliquots were resolved by SDS-PAGE (Laemmli 1970). The resolving gel contained $0.01 \%$ glycol chitin. After electrophoresis, the chitinolytic activity was detected essentially as described earlier (Marek et al. 1995). Proteins with chitinolytic activity appeared as clear zones on a dark brown background. Extracts from $S$. fredii USDA191 carrying chiB revealed chitinase activity associated with a $56-\mathrm{kDa}$ protein (Fig. 1). Addition of genistein, an isoflavonoid that induces the expression of nodulation genes of $S$. fredii, had no effect on the chitinase activity (Fig. 1, lane 3). Protein extracts from $S$. fredii carrying the vector pRK415 alone revealed no chitinase activity (Fig.1, lane 1). This result confirmed that the $S$. marcescens $c h i B$ was being expressed in $S$. fredii. Subcellular fractionation of the cell extracts from $S$. fredii USDA191 expressing $c h i B$ revealed that the chitinase activity was associated with the cytosol and the periplasm (data not shown). The estimated molecular mass of the chitinase was $56 \mathrm{kDa}$, which is the same size as the one expressed in $S$. marcescens (Brurberg et al. 1995).

We also investigated the consequence of expressing the chitinase in $S$. fredii on soybean nodulation. Seeds of soybean

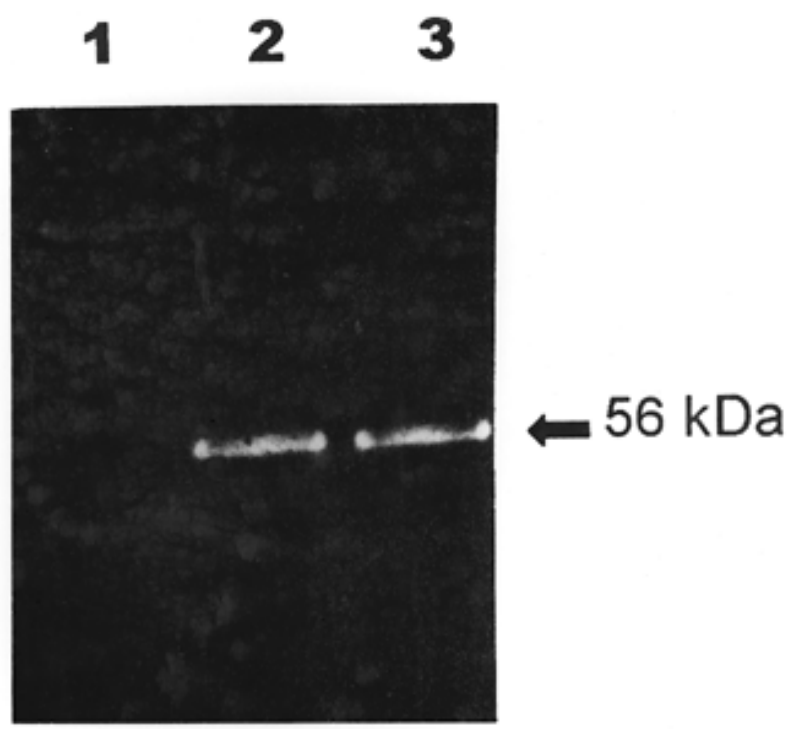

Fig. 1. Expression of Serratia marcescens chitinase in Sinorhizobium fredii USDA191. Total proteins were resolved on a $13.5 \%$ sodium dodecyl-polyacrylamide electrophoresis gel and the chitinolytic activity was detected by silver stain. The resolving gel contained $0.01 \%$ (wt/vol) glycol chitin. Lane 1: USDA191 (pRK415); lane 2: USDA191 (pSMC1); and lane 3: USDA191 (pSMC1) grown in the presence of $1 \mu \mathrm{M}$ genistein. $\beta$-Mercaptoethanol was omitted in all protein samples.
(Glycine $\max (\mathrm{L}$.$) Merr.) cultivar McCall were surface steril-$ ized and germinated on water agar plates at $30^{\circ} \mathrm{C}$. The roots of 3-day-old soybean seedlings were dip inoculated with cells of USDA191 containing either $c h i B$ or the cloning vector pRK415 ( $10^{8}$ cells per $\left.\mathrm{ml}\right)$. The seedlings were transferred to autoclaved plastic growth pouches that had been prewetted with distilled water. Soybean plants were grown in a growth chamber and the appearance of the nodules was monitored from day 5 after inoculation and alternate days thereafter until day 20. The kinetics of nodulation and final nodule numbers induced by USDA191 (pSMC1) were drastically different from those of USDA191 (pRK415). Chitinase-producing USDA191 exhibited delayed nodulation, with the nodules first visible at 9 days after inoculation (Fig. 2). At day 20, McCall soybean inoculated with USDA191 (pRK415) had 32 nodules per plant, while the chitinase-producing strain had only 12 nodules per plant. We also measured the nodule acetylene-reduction rates by the method of Schwinghamer et al. (1970). The nitrogenase activity expressed on a nodule fresh weight basis was similar between these two treatments (data not shown).

$S$. fredii synthesizes an array of Nod factors consisting of a series of $\beta$-1,4-linked oligomers of $N$-acetyl-D-glucosamine, with degrees of polymerization ranging from three to five (Bec-Ferte et al. 1994 and 1996). Chitinase readily digests the Nod factors of $S$. fredii and breaks down into chitobiose and chitorioses (Bec-Ferte et al. 1996). In order to examine whether expressing chitinase in $S$. fredii had any effect on the Nod factors, we labeled the USDA191 cells with ${ }^{14} \mathrm{C}$-acetate in the presence and absence of $1 \mu \mathrm{M}$ genistein. Supernatant from the labeled cultures was loaded on a C18 reversed-phase SepPak cartridge (Waters Corp., Milford, MA). The column

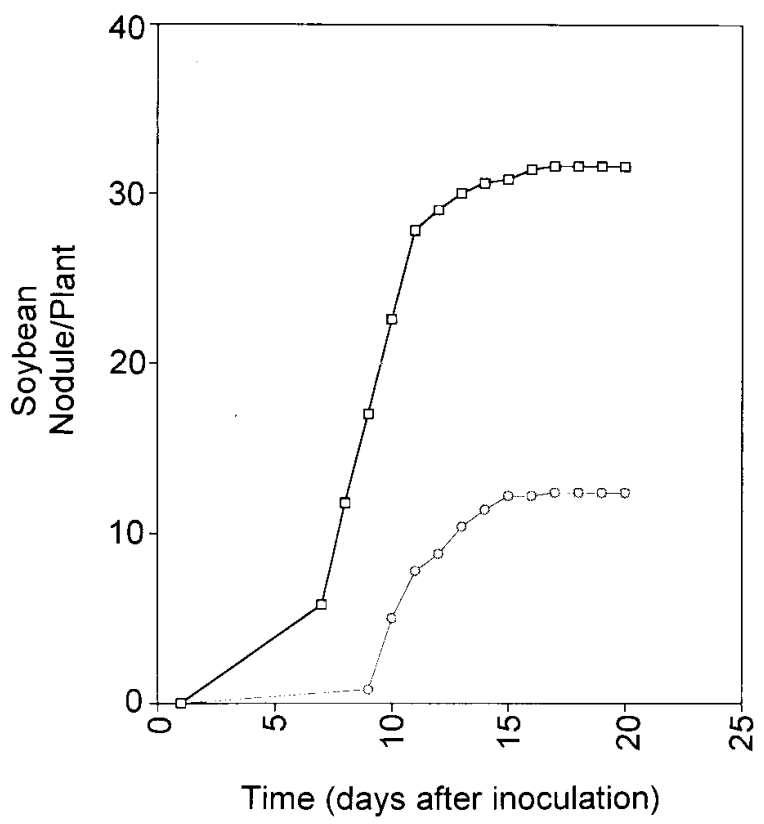

Fig. 2. Nodulation of cv. McCall soybean by Sinorhizobium fredii USDA191 expressing Serratia marcescens chitinase. Seedlings were inoculated with either USDA191 (pRK415) (circles) or USDA191 (pSMC1) (squares). Each point represents the mean nodule number from 32 plants from two independent experiments. Standard errors were less than $9 \%$ of means. 


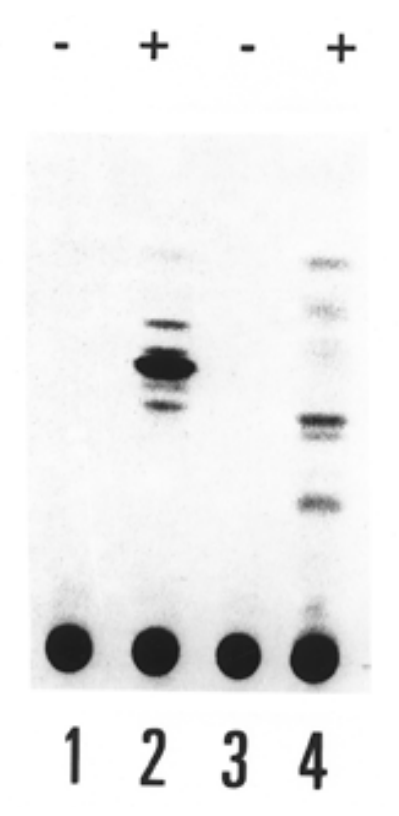

Fig. 3. Thin-layer chromatography (TLC) analysis of radiolabeled compounds produced by Sinorhizobium fredii USDA191. Bacteria were grown in presence of ${ }^{14} \mathrm{C}$-acetate in the presence or absence of $1 \mu \mathrm{M}$ genistein. Radiolabeled compounds were resolved on octadecyl silica reversed-phase TLC plates and subjected to autoradiography. Samples: lane 1, S. fredii USDA191(pRK415), lane 2, S. fredii USDA191 (pRK415) grown in the presence of $1 \mu \mathrm{M}$ genistein; lane 3, S. fredii USDA191(pSMC1); lane 4, S. fredii USDA191(pSMC1) grown in the presence of $1 \mu \mathrm{M}$ genistein.

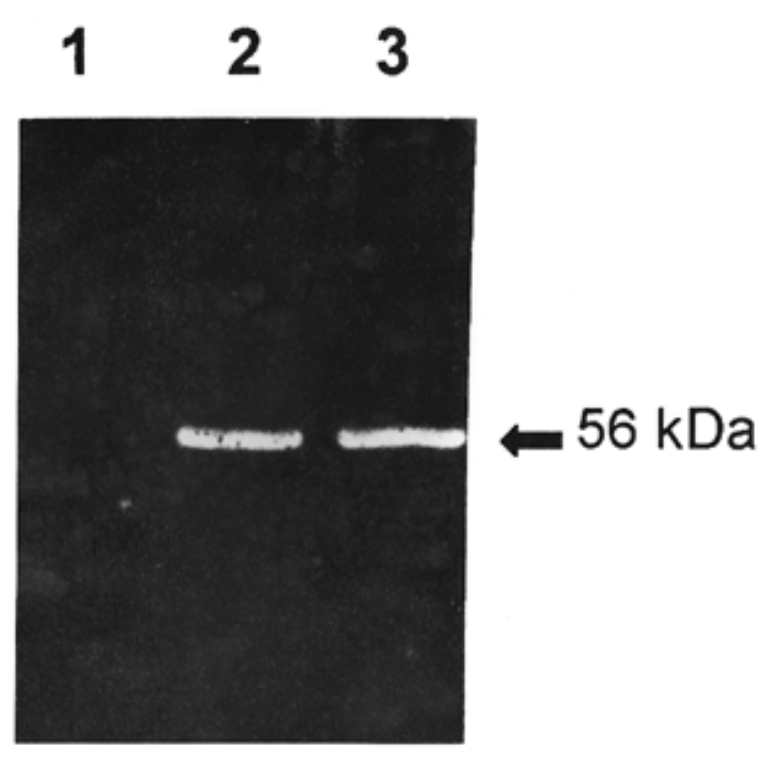

Fig. 4. Expression of Serratia marcescens chitinase in Sinorhizobium meliloti RCR2011. Total proteins were resolved on a $13.5 \%$ sodium dodecyl sulfate-polyacrylamide electrophoresis gel and the chitinolytic activity was detected by silver stain. The resolving gel contained $0.01 \%$ (wt/vol) glycol chitin. Lane 1: RCR2011 (pRK415); lane 2: RCR2011 (pSMC1); lane 3: RCR2011 (pSMC1) grown in the presence of $1 \mu \mathrm{M}$ luteolin. $\beta$-Mercaptoethanol was omitted in all protein samples. was washed with water and the Nod factors were eluted with methanol and concentrated to about $100 \mu$ l. Nod factors were resolved on octadecyl silica reversed-phase thin-layer chromatography (TLC) plates as described earlier (Bec-Ferte et al. 1994). Labeled Nod factors were visualized by autoradiography. Figure 3 shows at least four ${ }^{14} \mathrm{C}$-labeled spots from the culture of USDA191 that had been grown in the presence of genistein (Fig. 3, lane 2). These radioactive spots were absent in uninduced cultures of USDA191 (Fig. 3, lane 1). The chitinase-producing USDA191 also revealed several ${ }^{14} \mathrm{C}$ labeled spots, but their $R_{f}$ values were different from those of the non-chitinase-producing strain. One heavily ${ }^{14} \mathrm{C}$-labeled spot seen in USDA191 (Fig. 3, lane 2) was missing in the chitinase-producing strain; instead, few additional spots were evident (Fig. 3, lane 4). These results indicated that the Nod factors were being hydrolyzed by $S$. marcescens chitinase, resulting in altered Nod factors.

Earlier, Sitrit et al. (1993) reported $R$. meliloti expressing $S$. marcescens chitinase did not influence nodule formation, plant growth, or nitrogen fixing ability of alfalfa. In addition, these authors showed that protein extracts from nodules initiated by chitinase-producing Rhizobium spp. were able to degrade the hyphal tips of $R$. solani. We also tested the extracts from soybean nodules initiated by chitinase-producing and non-producing strains of USDA191, and found that both extracts were able to lyse $R$. solani hyphal tips. The protein extracts from soybean root nodules contained multiple chitinase activity as visualized by the SDS-PAGE/silver chitinolytic activity stain (data not shown). We believe that the lysis of $R$. solani hyphal tips was probably mediated by plant chitinases. We also wanted to test whether expressing the $c h i B$ gene in $S$. meliloti had any adverse effect on alfalfa nodulation. We

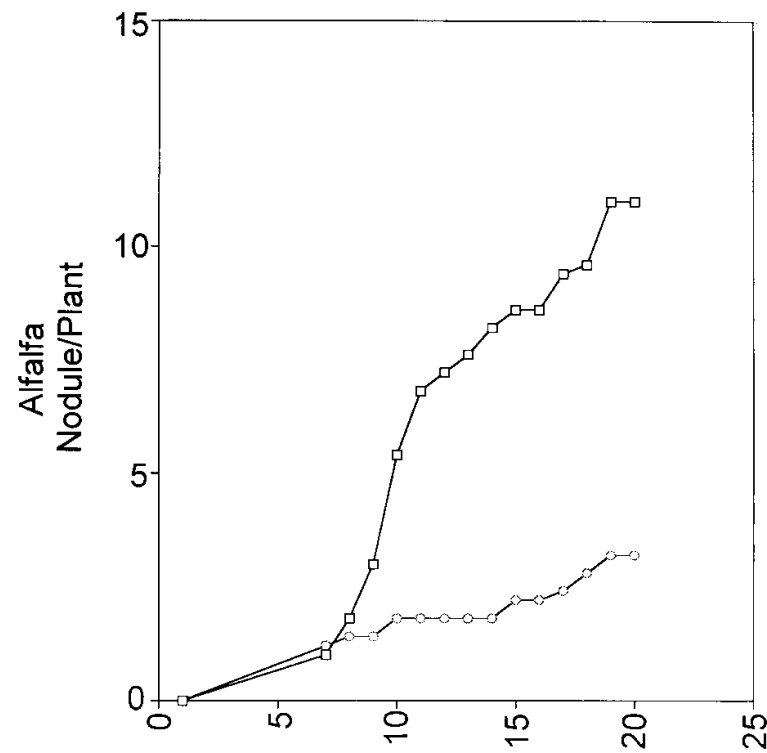

Time (days after inoculation)

Fig. 5. Nodulation of alfalfa cv. Nitro by Sinorhizobium meliloti RCR2011 expressing Serratia marcescens chitinase. Seedlings were inoculated with either RCR2011 (pRK415) (circles) or RCR2011 (pSMC1) (squares). Each point represents the mean nodule number from 32 plants from two independent experiments. Standard errors were less than $7 \%$ of means. 
therefore mobilized the chiB construct into $S$. meliloti RCR2011 and verified whether the transconjugants can produce chitinase. SDS-silver stain chitinolytic activity gels clearly established that the transconjugants were able to produce chitinase of about $56 \mathrm{kDa}$ (Fig. 4). Chitinase-producing RCR2011 also exhibited delayed nodulation and reduced nodule numbers on alfalfa cv. Nitro (Fig. 5). Therefore, it is evident that expressing the $c h i B$ gene in RCR2011 does affect nodulation. This result differs from the earlier study (Sitrit et al. 1993). This could be due to the fact that we expressed chiB, while the other study expressed chiA. chiA encodes the most abundant chitinase in $S$. marcescens and it is secreted in culture media. $c h i B$, on the other hand, is localized in the periplasm and is found in the culture medium only after prolonged culturing times, presumably due to cell lysis (Fuchs et al. 1986; Jones et al. 1986; Brurberg et al. 1995). It is most likely that the subcellular location of the chitinase could have a direct influence on the breakdown of the Nod factors. Since Nod factors accumulate primarily in the membranes (Orgambide et al. 1995), the periplasmic-located chitinase may be best suited to act on these signal molecules.

\section{ACKNOWLEDGMENTS}

This work was supported by a special grant from the United States Department of Agriculture, and is Journal Series No. 12,900 of the Missouri Agricultural Experiment Station. We thank May Brurberg for providing us with $S$. marcescens chiB plasmid (pMAY2-10) and Jerry White for critical reading of the manuscript.

\section{LITERATURE CITED}

Bec-Ferte, M. P., Krishnan, H. B., Prome, D., Savagnac, A., Pueppke, S. G., and Prome, J. C. 1994. Structures of nodulation factors from the nitrogen-fixing soybean symbiont Rhizobium fredii USDA257. Biochemistry 33:11782-11788.

Bec-Ferte, M. P., Krishnan, H. B., Savagnac, A., Pueppke, S. G., and Prome, J. C. 1996. Rhizobium fredii synthesizes an array of lipooligosaccharides, including a novel compound with glucose inserted into the backbone of the molecule. FEBS Lett. 393:273-279.

Broglie, K., Chet, I., Holliday, M., Cressman, R., Biddle, P., Knowlton, S., Mauvals, C. J., and Broglie, R. 1991. Transgenic plants with enhanced resistance to the fungal pathogen Rhizoctonia solani. Science 254:1194-1197.

Brurberg, M. B., Eijsink, V. G. H., Haandrikman, Venema, G., and Nes, I. F. 1995. Chitinase B from Serratia marcescens BJL200 is exported to the periplasm without processing. Microbiology 141:123-131.

Fuchs, R. L., McPherson, S. A., and Drahos, D. J. 1986. Cloning of a Serratia marcescens gene encoding chitinase. Appl. Environ. Microbiol. 51:504-509.
Jones, J. D. G., Grady, K. L., Suslow, T. V., and Bedbrook, J. R. 1986. Isolation and characterization of genes encoding two chitinase enzymes from Serratia marcescens. EMBO J. 5:467-473.

Keen, N. T., Tamaki, S., Kobayashi, D., and Trollinger, D. 1988. Improved broad-host range plasmids for DNA cloning in Gram-negative bacteria. Gene 70:191-197.

Laemmli, U. K. 1970. Cleavage of structural proteins during the assembly of the head of bacteriophage T4. Nature 227:680-685.

Mankau, R., and Das, S. 1969. The influence of chitin amendment on Meloidogyne incognita. J. Nematol. 9:192-197.

Marek, S. M., Roberts, C. A., Beuselinck, P. R., and Karr, A. L. 1995. Silver stain detection of chitinolytic enzymes after polyacrylamide gel electrophoresis. Anal. Biochem. 230:184-185.

Mercer, C. F., Greenwood, D. R., and Grant, J. L. 1992. Effect of plant and microbial chitinase on the eggs and juveniles of Meloidogyne hapla Chitwood (Nematoda: Tylenchida) Nematologica 38:227-236.

Mian, I. H., Godoy, G., Shelby, R. A., Rodriguez-Kabana, R., and Morga-Jones, C. 1982. Chitin amendments for control of Meloidogyne arenaria in infested soil. Nematropica 12:71-84.

Miller, P. M., and Sands, D. C. 1977. Effects of hydrolytic enzymes on plant-parasitic nematodes. J. Nematol. 9:192-197.

Minic, Z., Brown, S., De Kouchkovsky, Y., Schultze, M., and Staehelin, C. 1998. Purification and characterization of a novel chitinaselysozyme, of another chitinase, both hydrolysing Rhizobium meliloti Nod factors, and of a pathogenesis-related protein from Medicago sativa root. Biochem. J. 332:329-335.

Monreal, J., and Reese, E. 1969. The chitinase of Serratia marcescens. Can. J. Microbiol. 15:689-696.

Orgambide, G. G., Lee, J., Hollingsworth, R. I., and Dazzo, F. 1995 Structurally diverse chitolipooligosaccharide Nod factors accumulate primarily in membranes of wild type Rhizobium leguminosarum biovar trifolii. Biochemistry 34:3832-3840.

Schlumbaum, A., Mauch, A., Vogeli, U., and Boller, T. 1986. Plant chitinases are potent inhibitors of fungal growth. Nature 324:365-367.

Schwinghamer, E. A., Evans, H. J., and Dawson, M. D. 1970. Evaluation of effectiveness in mutant strains of Rhizobium by acetylene reduction relative to other criteria for $\mathrm{N}_{2}$ fixation. Plant Soil 33:192-212.

Shapira, R., Ordentlich, A., Chet, I., and Oppenheim, A. B. 1989. Control of plant diseases by chitinase expressed from cloned DNA in Escherichia coli. Phytopathology 79:1246-1249.

Sitrit, Y., Barak, Z., Kapulnik, Y., Oppenheim, A. B., and Chet, I. 1993. Expression of Serratia marcescens chitinase gene in Rhizobium meliloti during symbiosis on alfalfa root. Mol. Plant-Microbe Interact. 6:293-298.

Staehelin, C., Granado, J., Muller, J., Wiemken, A., Mellor, R. B., Felix, G., Regenass, M., Broughton, W. J., and Boller, T. 1994. Perception of Rhizobium nodulation factors by tomato cells and inactivation by root chitinases. Proc. Natl. Acad. Sci. USA 91:2196-2200.

Sundheim, L., Poplawsky, A. R., and Ellingboe, A. H. 1988. Molecular cloning of two chitinase genes from Serratia marcescens and their expression in Pseudomonas species. Physiol. Mol. Plant Pathol. 33: 483-491.

Vincent, J. M. 1970. A Manual for the Practical Study of Root-Nodule Bacteria. Blackwell Scientific Pub., Oxford.

Weller, D. M. 1988. Biological control of soilborne plant pathogens in the rhizosphere with bacteria. Annu. Rev. Phytopathol. 26:379-407. 